\title{
When pregnancy is a research risk
}

\author{
Ronald M. Green ${ }^{1}$ (ID
}

Received: 17 July 2020 / Accepted: 2 September 2020 / Published online: 10 September 2020

(C) Springer Science+Business Media, LLC, part of Springer Nature 2020

\begin{abstract}
A published study reported by Munné using uterine lavage to retrieve in vivo blastocysts for preimplantation genetic testing has been the subject of several technical and ethical critiques. None of these critiques has been based on a review of the study's IRBapproved informed consent. This commentary seeks to do that, examining the Munné (and related Nadal) consent forms for their conformity to existing requirements for a full and informed consent.
\end{abstract}

In 2019, Munné et al. published a study in Human Reproduction describing research conducted in Mexico using uterine lavage to retrieve in vivo blastocysts produced after IUI for preimplantation genetic testing (PGT) purposes [1]. At about the same time, Nadal et al. published another report of the same research in the journal Medical Devices: Evidence and Research [2].

These protocols sought to study the efficacy of a proprietary lavage device (Previvo Genetics, Inc.) and determine its usefulness in facilitating preimplantation testing (PGT) of the resulting embryos (as compared with embryos produced through standard IVF). The 81 participants were mostly oocyte donors, although a small number were infertility patients who were promised future treatment in return for their participation. Divided into natural cycle and $\mathrm{COH}$ groups, participants were inseminated with donor or partner sperm via IUI, and lavage was performed an average of 121 hours later. Following lavage, the participants were dosed with a GnRH antagonist to cause menstruation and reduce the risk of pregnancy should the procedure not recover all preimplantation embryos. Fourteen days after IUI, patients returned to the clinic for a "menses visit," a final blood draw for a pregnancy test measuring hCG. Those found with elevated hCG either were administered methotrexate or underwent a D\&C to terminate the pregnancy.

From its first publication, this report was recognized as raising ethical questions. In conjunction with the Munné

Ronald M. Green

Ronald.M.Green@Dartmouth.edu

1 Department of Religion, Dartmouth College, Hanover, NH, USA publication, the editorial team of Human Reproduction published an editorial explaining their decision to publish the report.

We received all requested documents that verified IRB approval from both the USA-based Western Institutional Review Board (WIRB) and the Ministry of Health of the State of Nayarit in Mexico, where the interventions were carried out. Furthermore, we received fully informative patient information sheets both in English and in Spanish, which indeed detailed all the potential disadvantages for the study participants including the risks of ovarian hyperstimulation syndrome and MTX and D\&C treatment consequences, in case of an inadvertent pregnancy. The financial compensation amounted to $\$ 1400$ for each participant. This documentation convinced the Editorial Team that all necessary steps were truly taken for ethical approval. . . . Two ethical boards have evaluated the content and accepted the project under the guidance of this [the Helsinki] declaration. Are we entitled to overrule two Ethical boards (one American and one Mexican) that approved the study? [3]

It is not clear from these remarks that the editorial team actually reviewed the informed consent documents for this research. They speak of "fully informative patient information sheets both in English and in Spanish." Were these in fact the protocol's informed consent documents as approved by the Western Institutional Review Board?

The same issue published an Editorial Commentary by its Associate Editor, Galia Oron [4]. This raised several ethical concerns about the Munné study. In May 2020, JARG published a critique of the study by De Santis et al. Speaking for the leadership of the Italian Society of Embryology, 
Reproduction and Research (SIERR), the JARG article contended that the Munné study was "undermined by severe technical and ethical issues" [5].

Both critiques raised important questions. But lacking discussions of the informed consent for each protocol, they could neither address nor answer a central ethical question raised by this research: Were the research participants fully and accurately informed of all the risks of this study? Replying to my requests, the researchers have now furnished me with those consent documents. Following a review of the Oron and De Santis critiques, I will turn to those documents.

Oron's concerns are based on each of the four major principles of medical ethics: autonomy, justice, beneficence, and non-malfeasance [sic]: Autonomy because the inclusion of participants enlisted to an oocyte donation program with future monetary benefits "raises the inevitable question as to their incentive for participating in this study"; Justice because the recruitment of the same patient "to two studies necessitating consecutive fertility ovarian stimulation ... does not seem to distribute benefit and burden"; Beneficence because the study impregnates fertile women "only to then terminate the pregnancy for future technological advancement"; Nonmalfeasance [sic] because of "the relatively low embryo recovery rate (42\%), the need for a double embryo biopsy in the majority of cases $(90 \%)$ and the significant side effect of a persistent positive beta-hCG warranting methotrexate treatment."

De Santis et al. echo Oron's questioning about whether the Munné study complies with the four major precepts of medical ethics. They voice particular concern "that $8 \%$ of the socalled oocyte donors had an unintended conception as a result of a failed uterine lavage procedure and therefore underwent a pharmacologically induced (via methotrexate) and/or surgical (via curettage) abortion.” They continue,

it is unclear whether the enrolled women were informed about the risk for an unintended pregnancy requiring them to undergo an abortion. In this regard, two further important doubts are raised: was the word "abortion" (or similar) used in the consent? Were the women who conceived as a result of a failed uterine lavage procedure provided with a medical and psychological counseling before deciding whether to have an abortion?

With the actual consents in hand, we can now answer De Santis et al.'s questions. But first, it is useful to identify the main requirements for an informed consent to research like this. We can then see how well the Munné/Nadal consents measure up.

In a protocol with many steps like this one, it is important that a consent makes clear that a participant can terminate her involvement at any time without undue penalties. Equally important, the consent must explain the planned procedures and risks in terms the research participants can understand and evaluate. This is made clear in the Code of Federal Regulations (21CFR50.20), which states "The information that is given to the subject or the representative shall be in language understandable to the subject or the representative." Since the research participants here were young Mexican women, this requirement calls for the use of language that was not just understandable to them but that also allowed them to weigh their values and facilitated their free and voluntary choice. In view of these requirements, how well did the consent for this research do?

In terms of refusing continued participation both the English and Spanish version of the consent is clear. Under the heading "Voluntary Participation," it states:

Your ongoing participation in this study is voluntary and you can terminate the study at any time by informing your study doctor, without incurring any consequences, or becoming in anyway disadvantaged. You must inform the study doctor of any decisions regarding a change in your participation. Any rejection of participation in the study will have no effect on your future relationship with the principal investigator or with the study center. However, if you withdraw from the study after the procedure and during the follow-up period, this means that your health status will no longer be monitored under the study conditions. Follow-up examinations will continue to take place on a schedule determined by your doctors $[6$, p. 3$]$.

Later on, under the heading "Study Withdrawal," the consent states:

The decision to be in this study is up to you. You have the right to leave this study at any time. If you decide to not participate or do not want to continue to be in the study, there will be no penalty to you, and you won't lose any benefits that you are entitled to [6, p. 18].

In connection with this, the consent also assures participants:

In case of an injury related to this research study: Treatment will be offered if you have an injury or problem as a result of being in this study. If you have any problems directly from the use of the Previvo System, Previvo Genetics will pay for the reasonable costs of medical treatment that is not covered by your health insurance or other provider [6, p. 17]. 
These assurances are required and appropriate. But in the context of this study, they raise further important questions. Can a woman drop out of the study following lavage and choose to continue any pregnancy (or multiple pregnancies) she is carrying? Does this right to withdraw from the study extend to doing so at the 14-day post-lavage "menses visit" blood draw for a pregnancy test? Can she choose do so following a positive pregnancy test? And if a women chooses to withdraw and continue her pregnancy, will Previvo Genetics cover the reasonable costs of her care through birth and, if necessary, beyond? Recall that De Santis et al. asked, "Were the women who conceived as a result of a failed uterine lavage procedure provided with a medical and psychological counseling before deciding whether to have an abortion?" The consent offers no answer to any of these questions. Of course, consent is a process that may include verbal counseling in addition to the written consent. Although the full consent process here may have included counseling that addressed these issues during the pre-Menses or menses visit, the form itself makes no mention of them.

This lack of mention becomes more concerning when we look at the precise language describing the menses visit. Under the description of the research, it reads:

You will return to the clinic for a final blood draw (10 $\mathrm{mL}$, two $5 \mathrm{~mL}$ tubes, $2 \mathrm{tsp}$ ) to measure hCG (pregnancy test). In the unlikely scenario that positive hCG is detected, the study doctor may treat you for a pregnancy of unknown location (PUL, see page 9). In some cases, this may require additional treatment using a commonly used medication (Methotrexate) and/or a removal of a portion of the uterine lining (dilation \& curettage) $[6, p .6]$

(Here is the Spanish version of this text. As is true everywhere in the two documents, it closely matches the English:

\section{Deberá regresar a la clínica para hacerse una extracción final de sangre $(10 \mathrm{ml}$; dos tubos de $5 \mathrm{ml}$ [2 cucharaditas]) para determinar la hCG (prueba de embarazo). En el caso improbable de que se detecte la presencia de hCG, el médico del estudio podría tratarla como si hubiera un embarazo en una localización desconocida (ELD; página 9). En algunos casos, esto podría requerir otro tratamiento con un medicamento de uso frecuente (metotrexato) y/o la eliminación de una parte del revestimiento uterino (dilatación y legrado) $[7$, p. 6])}

Similar language is later used in an extended section describing the risks of the research:

The following risks are associated with the study protocol:
1. Pregnancy of unknown location (PUL)

A "pregnancy of unknown location" is a situation where there is a positive serum pregnancy test, but there are no signs of intrauterine (inside the uterus) pregnancy, or an extrauterine (outside the uterus) pregnancy via ultrasound. The uterine lavage procedure is designed to remove preimplantation embryos before pregnancy can occur but, in some lavages, embryos may not be successfully collected by the lavage procedure and may lead to a PUL. A serum pregnancy test is conducted at the menses visit to confirm you are not at risk of a PUL. Should you present a positive serum pregnancy test, your study doctor may elect use of the following preventative treatments:

(The Spanish version of this last sentence reads: "Si usted presenta un resultado positivo en la prueba de embarazo en suero, puede que el médico del estudio decida administrarle uno de los siguientes tratamientos preventivos." [7, p. 12]).

Methotrexate (MTX): MTX is a drug used to cause the termination of the PUL and prevent further complications.

(The Spanish version of this last sentence reads: "Metotrexato (MTX): El metotrexato es un medicamento que causa la terminación de un embarazo en una localización desconocida e impide que surjan más complicaciones." [7, p. 12]).

MTX works by preventing the cells of an early pregnancy to multiply, causing these cells to die. Successful treatment with MTX can reduce the need for surgery due to an abnormal pregnancy. More than $88-95 \%$ of patients treated with methotrexate do not need surgery.

Although the risk of PUL following lavage is low, we want you to be fully informed of the risks associated with the use of MTX. ... (The consent form here further describes the physiological risks of MTX.) . . .

Dilation and curettage $(D \& C): \mathrm{D \& C}$ is a procedure in which a thin instrument is inserted into the uterus, and the instrument is used to remove tissue from the inside of the uterus. A D\&C may be used to treat or establish a diagnosis for positive pregnancy. Possible risks and complications from the $\mathrm{D} \& \mathrm{C}$ may include heavy bleeding, infection in the uterus or other pelvic organs, perforation or puncture to the uterus, laceration or weakening of the cervix, and scarring of the uterus or cervix. After the procedure, some light cramping and bleeding are expected like a menstrual period [6, pp. 11-12].

What is notable here is the absence in both English and Spanish of use of the term "abortion." (The Spanish term would be "aborto.") Both methotrexate and D\&C are presented as "preventative treatments" for what is variously described as "a positive hCG," "positive serum pregnancy test," or "pregnancy of unknown location (PUL)."

The Roman Catholic religion, to which we can reasonably presume that many of this study's participants adhere, regards 
abortion as a "grave sin" whose commission can lead to excommunication and possible exclusion from eternal salvation [8]. Whether or not all study participants shared these beliefs, full and informed consent requires that the term "abortion" be used so that participants can determine whether they wish to chance these spiritual risks. Obscuring this by describing chemical or surgical abortion as a "treatment" for "positive hCG" or a "pregnancy of unknown location" does not appear to meet the language requirement of a proper consent form.

This protocol and its consent form were approved by the Western IRB (WIRB), an independent commercial IRB located in Olympia, WA. It is not known whether the WIRB board considered the adequacy of the consent's use of language. Also, it is worth reiterating that a consent form is only part of a more complete consent process. The consent form itself does begin with the following bold-faced advisory: "This consent form may contain words that you do not understand. Ask the Study Doctor or study staff or research team to explain any words that you do not clearly understand" [6, p. 1]. Although the published reports by Munné or Nadal provide no information about such a process, it is possible that information was provided verbally to the participants that afforded them a more complete and accurate understanding of the risks this research posed for them.

Let me conclude by offering briefly what I believe would have been more appropriate language in a consent form for these studies. I will leave it to the reader to determine what more might be said and whether the actual consent form measures up.

You will be inseminated to become pregnant with one or more early embryos. At about 5 days after this, these embryos will be washed from your womb for further study. No embryos will be allowed to develop further. There is the possibility that not all embryos will be washed out. Fourteen days after insemination, you will be tested to see whether you are pregnant with any remaining embryos. If you are, and if you consent, we will perform a chemical or surgical abortion. You can withdraw from this study at any time, including before the abortion. However, if you withdraw from the study after the procedure and during the follow-up period, this means that your health status or pregnancy will no longer be monitored under the study conditions. Follow-up examinations will continue to take place on a schedule determined by your doctors.

\section{References}

1. Munné S, et al. First PGT-A using human in vivo blastocysts recovered by uterine lavage: comparison with matched IVF embryo controls. Human Reprod. 2019;35(1):70-80 (Advance Access Publication on December 30, 2019). https://academic.oup.com/ humrep/article/35/1/70/5678546.

2. Nadal A, Najmabadi S, Addis B, Buster JE. Novel uterine lavage system for recovery of human embryos fertilized and matured in vivo. https://www.dovepress.com/novel-uterine-lavage-systemfor-recovery-of-human-embryos-fertilized-a-peer-reviewed-articleMDER.

3. Lambalk CB, VanWely M, Kirkegaard K, De Geyter C. Ethics beyond ethics. Hum Reprod. 2020;35(1):1-2 https://academic.oup. com/humrep/article/35/1/1/5689794.

4. Oron G. How far should we go in the name of science? Hum Reprod. 2020;35(1):3-4 https://academic.oup.com/humrep/article/35/1/3/ 5689793.

5. De Santis L, et al. IUI and uterine lavage of in vivo-produced blastocysts for PGT purposes: is it a technically and ethically reasonable perspective? Is it actually needed?" J Assisted Reprod Genet. 2020. https://link.springer.com/article/10.1007/s10815-020-01813-7.

6. Previvo Genetics, Inc. TD 2104-1 Study Informed Consent, Approved as Modified, June 14, 2018, WIRBß.

7. Previvo Genetics, Inc. TD 2104-2 Consentimiento Informado del Estudio, Approved as Modified, June 14, 2018, WIRB®.

8. Catechism of the Catholic Church. 1992. Part Three, Life in Christ, Section Two, The Ten Commandments, Chapter Two, Article 5, 2272. https://www.vatican.va/archive/ccc_css/archive/catechism/ p3s2c2a5.htm.

Publisher's note Springer Nature remains neutral with regard to jurisdictional claims in published maps and institutional affiliations. 